\title{
Reseñas
}

\section{El pasado prehispánico en la cultura nacional (memoria hemerográfica 1877 -I9II) \\ de Sonia Lombardo de Ruiz}

M éxico, Instituto N acional de Antropología e H istoria, I994, 2 vols. (Antologías, Serie Arqueológica)

por

BEATRIZ DE LA FUENTE

La labor profesional de Sonia Lombardo de Ruiz ha sido fecunda y regular; su espíritu inquieto la ha llevado a cursar varias carreras con el fin de tener mejores herramientas para aproximarse a los hechos artísticos del pasado de nuestro país. Los tiempos en los cuales ha concentrado su atención son el prehispánico, con la pintura mural maya, y la historia urbana moderna, en lo que va de T enochtitlan a la actual ciudad de M éxico.

Ahora sale a luz un gran trabajo de compendio, con esclarecedor estudio preliminar, sobre la información periodística de la época del gobierno de Porfirio D íaz referida a tiempos precolombinos. Es instrumento útil al conocimiento a la vez que elocuente interpretación de la autora.

El libro se constituye de dos volúmenes. El primero incorpora las notas periodísticas de El M onitor Republicano, entre 1887 y 1986 (339 artículos); el segundo abarca informaciones publicadas en El Imparcial, de 1897 a I9II (593 artículos).

En el estudio preliminar, la autora establece su postura teórica frente al acaecer histórico de los hechos que reseña. Así postula que, hacia finales del siglo xviı, se inicia una revaloración del universo prehispánico; surge el deseo de encontrar "antigüedades" y de justificar la identidad del criollo. Después de la independencia, la cultura y la historia antigua siguen siendo los pilares más sólidos para conformar la presencia ideológica de la nueva nación. Dice así la autora: "el fenóme no interno de búsqueda de la identidad se refuerza con otro de carácter universal que viene del extranjero: el romanticismo, que descubre, estudia, y valora las culturas no occidentales."

Al mismo tiempo que se advierte la recuperación de una conciencia nacional, se inicia el mercado de antigüedades, y con ello, poco después, el reglamento que define lo que es el patrimonio de la nación. M ás adelante, los objetos prehispánicos serían utilizados - costumbre política que aún subsistecomo "embajadores culturales". De ello dan cuenta los artículos periodísticos recopilados en el libro que me ocupa.

La autora señala un dato importante: en tanto que EI M onitor Republicano era un dia- 
DOI: http://dx.doi.org/10.22201/iie.18703062e.1995.66.1740

I66

rio del movimiento liberal, El Imparcial, que sustituyó al primero, recibía subsidio del gobierno.

$\mathrm{H}$ ay momentos en que los periódicos registran mayor número de artículos sobre hallazgos y comentarios del pasado precolombino. Así, en I882, las noticias cubren las hoy afamadas visitas de Charnay y de Le Plongeon; en I886 difunden los trabajos de Leopoldo Batres; en I892 se ocupan en conmemorar el Cuarto Centenario del D escubrimiento de América, y en i895 se da cuenta del interés despertado por el Congreso de Americanistas, efectuado por vez primera en la ciudad de M éxico.

Para rgoo la información fue abundante debido a las excavaciones de Batres en el Templo M ayor de Tenochtitlan; para igos las noticias se extienden, y en rigo y igir siguen en aumento debido a las exploraciones y visitas a Teotihuacan. La inauguración de la Escuela $\mathrm{N}$ acional de Antropología es motivo, a su vez, de amplios comentarios.

Del trabajo de Lombardo de Ruiz se hacen patentes dos tipos de testimonios que vale la pena comentar: por una parte se publican noticias de localización, hallazgos, exploraciones en torno a la arqueología mexicana. Por otra se difunden, reproduciéndolas, las noticias que sobre el tema publica la prensa internacional. De tal suerte que los sitios arqueológicos mencionados - y lo que de ellos deriva- son notablemente más numerosos durante la primera década de este siglo. Ello implica el registro de un proceso histórico que va paulatinamente afincando la conciencia social de un pasado indígena.

Para finales del siglo xix, el proceso culmina con la institucionalización de la arqueología. De aquí en adelante la autora entreteje su visión acerca de la historia decimonónica mexicana con datos y reseñas que la fundamentan.

$\checkmark$ eamos algunos puntos destacados: el resultado de la incipiente inquietud social debida a los saqueos fue la expropiación del chac-mool de Chichén Itzá, que su descubridor, Auguste Le Plongeon, iba a sacar del país - hoy engalana el $\mathrm{M}$ useo $\mathrm{N}$ acional de Antropología- ; el producto de la regulación de exploraciones y hallazgos arqueológicos fue el ordenamiento de que todos los bienes culturales de esta categoría se entregaran al M useo $\mathrm{N}$ acional; el consenso acerca de la ley que establecía la imposibilidad de conservar en calidad de "propiedad privada" todos los sitios en donde hubiera monumentos arqueológicos; la expropiación de predios con monumentos arqueológicos en Teotihuacan; la formación de una "cultura nacional" a través de la educación, que reivindicaba al indio del pasado - no se hablaba del indio contemporáneo- ; la proliferación de la actividad arqueológica; el registro institucionalizado de las acciones arqueológicas; la definición de las funciones del M useo $N$ acional y de la Inspección de M onumentos, y la proyección en el mundo del pasado prehispánico por medio de los visitantes extranjeros y por el envío de piezas prehispánicas para ser expuestas en distintas partes del mundo.

Q uise enumerar todas - 0 casi todaslas disposiciones capturadas por los diarios capitalinos que reproduce Sonia Lombardo Ruiz. Fueron, no cabe duda, medidas acordes a los tiempos del progreso. Parece que son actuales: ¿qué ocurrió con tales instrucciones? El trabajo de compilar esa información sustancial colabora en la lectura correcta sobre el proceso de aceptación y legislación del pasado prehispánico; es trabajo lento y constante, rehuido por no pocos investiga- 
dores; es una suerte de tabique que sirve de sostén al conocimiento.

Apoya, también, para reflexionar en torno de las sabias medidas que se establecieron sobre las antigüedades mexicanas; de modo tal que cabe una pregunta general para evaluarlas: ¿qué es, qué se ha llevado a cabo, qué se ha modificado 0 añadido a tan magníficas propuestas aceptadas hace decenios, por no decir una centuria? Sonia Lombardo de Ruiz nos otorga el instrumento necesario para esta reflexión.

$\$$

\section{Writing without words: Alternative Literacies in M esoamerica and the Andes} compilación de Elizabeth $\mathrm{H}$. Boone y W alter D. M ignolo

D urham y Londres, D uke U niversity

Press, 1994, 324 p., ilus.

por

MARIE-ARETI HERS

Este libro presenta algunos de los resultados de una mesa redonda llevada a cabo durante dos días de r99i en la D umbarton 0 aks, titulada "Art and Writing: Recording Knowledge in Precolombian America". Comprende doce trabajos cuya selección fue esencialmente temática y corresponde a los trabajos presentados en el primer día de dicho encuentro, dedicado a los sistemas icónicos y pictóricos mesoamericanos con dos estudios comparativos sobre los famosos quipus peruanos. Sin pretensión de exhaustividad, se analizan ciertos tipos de manuscritos desde distintos enfoques. Como lo indica el título del libro, el punto de convergencia de los autores es compartir un mismo interés por las escrituras que nos transcriben el discurso verbal y que consideran como escrituras alternativas.

Una clara presentación de esa manera de ver la escritura nos es ofrecida por Elizabeth Boone, editora de la obra, en su "Introduction: W riting and Recording Knowledge" (pp. 3-26). Es pertinente extendernos detalladamente sobre estas consideraciones iniciales para poder apreciar el libro, puesto que su definición de escritura es compartida por el conjunto de los autores.

En primer lugar, Boone recalca la nece sidad de una definición de escritura que rebase la tradicional, según la cual la evolución culmina necesariamente en la alfabetización. Constata que en esta estrecha perspectiva etnocéntrica, las escritura es vista como un lenguaje verbal visualizado $\mathrm{y}$, por ende, los sistemas de registro mesoamericanos no serían escrituras o serían formas muy primitivas y deficientes de transcribir el lenguaje verbal. La autora rechaza tal manera de ver las cosas, y fundamenta su posición en tres puntos centrales. En primer lugar, subraya la existencia de pensamientos que se describen, se interpretan y comunican mejor con los medios de visualización que a través del lenguaje hablado. Tales son los casos de las matemáticas, la música y los diagramas científicos. En segundo lugar, señala que cuando se trata de pensamientos que, efectivamente, se expresan mejor por el lenguaje hablado, la transcripción escrita tiene siempre serias limitaciones en cuanto a la dimensión temporal del discurso. Finalmente, anota lo históricamente erróneo del modelo evolucionista unilineal, según el cual se pasa 
necesariamente de la pictografía a la abstracción y a la fonetización, puesto que en el caso de M esoamérica los sistemas pictóricos mixtecos y mexicas sucedieron a los sistemas de los mayas y de los zapotecas, más escriturales en el sentido estricto de la palabra. Llega así a la conclusión de que la historia de la escritura no es un proceso que lleva necesa riamente al alfabeto, sino que es una serie de procesos evolutivos paralelos en los cuales cada sistema sigue su propio proceso de transformación.

Liberada así del yugo de definiciones tradicionales demasiado estrechas, Elizabeth Boone va en búsca de una definición globalizante de la escritura, adecuada para el estudio de los sistemas americanos precolombinos. Tal perspectiva, anota, es necesaria para entender mejor la antigüedad americana, pero también para apreciar con mayor lucidez el futuro de nuestro propio sistema de escritura y del libro mismo, destinados a desaparecer en cierta medida frente a la proliferación de los medios visuales de comunicación. La autora retoma así algunas de las ideas de la obra clásica de André Leroi G ourhan cuyos trabajos de hace más de tres décadas ya habían abierto la brecha para rechazar los conceptos demasiado etnocéntricos acerca de la escritura y para entender mejor los lenguajes visuales que no están subordinados al lenguaje hablado.

A partir de las obras de G elb, Hill y Sampsone, Boone elabora una definición suficientemente amplia de la escritura: "Ia comunicación, de modo convencional, de ideas relativamente específicas por medio de marcas visibles permanentes." Sobre esa base, distingue dos clases de escrituras: los sistemas glotográficos maya, zapoteca y de Veracruz y los semasiográficos de los mixtecos y los mexicas. Los primeros son una combinación de logogramas, de signos foné ticos y de calificadores semánticos; en ellos se distinguen signos principales y afijos; sirven para reproducir el texto verbal y se leen según un orden preestablecido. La diferencia entre el texto y la imagen es clara y actuan en armonía. Al contrario, los sistemas semasiográficos mesoamamericanos guardan una gran proporción de descripción visual, se acompañan de convenciones arbitrarias y se ordenan según lugares relativos. El orden de lectura no es muy preciso y pueden leerse en diferentes lenguas. Los textos y las imágenes están fundidos. La dicotomía arte escritura es improcedente puesto que es una fusión completa. Al establecer esas distinciones, Boone recuerda que, en M esoamérica, el sistema glotográfico antecedió por muchos siglos al sistema semasiográfico. La gran mayoría de los trabajos reunidos en la presente publicación tratan sobre este último sistema, con enfoques muy diversos.

En "Literacy among the Precolombian M aya: A Comparative Perspective" (pp. 2749), Stephen H ouston compara la realidad mesoamericana con el mundo mediterráneo, chino y japonés, recalcando las diferencias entre los escribanos y los lectores y las variaciones temporales en el acceso a la lectura. Para la cultura maya, busca determinar las variaciones regionales del papel de la escritura. Según el autor, una mayor proporción de lectores se ve reflejada por el aumento de anotaciones fonéticas a lo largo del Clásico. Llama la atención sobre los graffiti insuficientemente registrados, expuestos a los turistas y poco estudiados. Los considera una valiosa fuente de información para detectar los niveles de habilidad en la escritura.

En "Aztec Pictorial H istories: Records without W ords" (pp. 50-76), Elizabeth Boone revisa los tres géneros de discursos 
históricos de los cuales tenemos testimonios: lo que llama las res gettae, las historias cartográficas y los anales. Con la claridad que la caracteriza, los distingue en función de la importancia relativa que tiene en ellos cada uno de los cuatro aspectos fundamentales de los discursos históricos: los actores de la historia, las acciones emprendidas, el espacio y el tiempo. Con base en ejemplos concretos, demuestra cómo cada uno de esos tres tipos de discursos históricos se adapta a las funciones sociopolíticas de los relatos. En el caso de las res gestae, se trata de fortalecer los poderes de linajes gobernantes, en el de las historias cartográficas de relatar migraciones y dominios territoriales y en el caso de los anales de servir a un poder imperial. Recalca esa capacidad de adaptar el discurso a la función, con la presentación de casos en los cuales se combinan esas tres formas discursivas para mejor servir a los propósitos de la historia.

En un breve ensayo titulado "Voicing the Painted Image: A Suggestion for Reading the Reverse of the Codex Cospi" (pp. 7786), Peter $V$ an der Loo retoma dos ideas centrales de sus antecesores en el estudio de los códices del grupo Borgia. De M aarten Jansen retoma la propuesta de que la diferencia entre los códices de ese grupo y de los mixtecos es menor de lo supuesto y más que una diferencia entre textos religiosos e históricos se trata de la diferencia entre textos prescriptivos y descriptivos, respectivamente. En esa perspectiva, propone ir más allá del simple listado de los elementos visibles de los códices del grupo Borgia e intentar una lectura textual similar a la que se hace con los códices mixtecos. Por otra parte, el autor concuerda con N owotny en considerar el reverso del códice Cospi como un texto de prescripciones rituales de cacería, compara- ble a las oraciones recopiladas por Schultze Jena entre los tlapanecos de Guerrero en los años treinta. $V$ an der Loo retoma ese mismo camino, basándose además en su propio trabajo de campo entre los tlapanecos. De esa manera, y con base en las premisas de la unidad religiosa mesoamericana y de su persistencia tras siglos de conquista, propone una lectura del reverso del códice en la cual se reconocen las tres partes que conforman el ritual de cacería tlapaneca. El evidente inte rés de la lectura se ve limitado desgraciadamente por lo corto de ese ensayo, puesto que se restringe a la lectura de una sola página del códice. Las conclusiones que saca el autor son triples. Como el Cospi no es un códice tlapaneco, su lectura a partir de oraciones en un idioma distinto al del escribano ilustra cómo ese sistema de registro se adapta exitosamente a un mundo mesoamericano esencialmente políglota. También recalca el hecho de que ese sistema no se preocupa por anotar un texto palabra por palabra, sino que persiste cierta independencia del lengua je visual en relación con el hablado. D e esa manera, para el lector antiguo del manuscrito se manifestaba cierta flexibilidad regional o personal. Tal realidad era particularmente bien adaptada a la religión panmesoamericana muy poco preocupada por los dogmas. Finalmente, subraya la necesidad de ir más allá de una simple lista de elementos visibles para intentar una lectura de esos códices. Se necesita, según $V$ an der Loo, buscar el impacto emocional que creaba sobre sus lectores.

En el siguiente ensayo, igualmente bre ve, titulado "The Text in the Body, the Body in the Text: The Embodied Sign in M ixtec W riting" (pp. 87-IoI), John M onaghan aborda las estrechas relaciones que existían entre el cuerpo y la escritura para los mixtecos. En una primera parte, recuerda 
cómo la lectura de los códices no se hacía solamente a través de la palabra sino que se trataba de una ejecución completa en la cual se conjugaban la danza, el canto, la gestua lidad y los trajes y adornos corporales. Enfatiza al respecto, cómo la separación entre canto, danza y oración es el propio del mundo occidental pero no del mesoamericano. En la segunda parte, revisa la importancia central que tiene el cuerpo en el texto de los manuscritos. No sólo abundan las figuras humanas con trajes elaborados y gestualidad estereotipada, sino que el cuerpo es la metáfora central para expresar relaciones espaciales, pero también familiares, sociales y políticas. Concluye señalando la necesidad ineludible de conocer mejor la gestualidad y las expresiones faciales, el simbolismo del cuerpo en general, antes de poder abordar la lectura de los códices mixtecos y del grupo Borgia.

EL estudio de M ark B. King, titulado "H earing the Echoes of V erbal Art in M ixtec Writing" (pp. I02-136), se subdivide en tres partes. Empieza por consideraciones semánticas sobre palabras como "libro", "escribir" y "cantar", y recuerda el hecho de que los manuscritos fueron escritos en el dialecto mixteco de la clase alta. Con base en esas primeras consideraciones, subraya cómo los códices pueden ser considerados metáforas visuales del canto, como acotaciones para una ejecución musical.

En la segunda parte, prosigue con la metáfora de la música y compara la interrelación de los diferentes niveles de significación en los escritos mixtecos con las combinaciones presentes en un cuarteto. Separa por su aspecto gramatical las categorías básicas de información transmitidas por esos escritos, como son las frases nominales, las frases verbales y los modificadores. Como en un texto musical, distingue una línea narrativa que evoca los cartoons, realzada visualmente por un complejo vocabulario simbólico basado en un lenguaje divinatorio poético. Retoma en particular la proposición de Caso de que el singular vocabulario del calendario sagrado mixteco, reflejo de un muy antiguo lenguaje ritual cantado, fue usado en los códices como sistema silábico para expresar los nombres de las divinidades y de los ancestros.

En la tercera parte, amplía y concreta las ideas expuestas con una lectura de algunas partes del códice de Viena y con comparaciones etnográficas del mundo mixteco actual. En particular enfatiza lo que concierne a "Siete flores" y "Uno muerte", y la estrecha relación entre humo y canto, calor y colores, amanecer y vitalidad, expresada por los distintos tipos de volutas. Concluye recomendando que las lecturas de los manuscritos mixtecos rebasen la simple búsqueda de datos históricos y se internen en la búsqueda de las metáforas culturales que se reflejan en el vocabulario simbólico y en su léxico.

En "M exican Codices, M aps and Lienzos as Social Contracts" (pp. 137-160), John M.D. Pohl se propone analizar diferentes usos del Ilamado estilo internacional o estilo mixteco-poblano, como reflejo de formas distintas de organización social. D e manera similar a lo que Elizabeth Boone presenta en el segundo capítulo del libro, se propone distinguir diferentes estrategias documentales para reportar el territorio y la historia. A tal efecto, ejemplifica con tres grupos de documentos: los mapas y lienzos mixtecos y zapotecos, la $\mathrm{H}$ istoria tolteca-chichimeca y los mapas de Cuauhtinchán $y$, finalmente, el grupo intermedio de los mapas y lienzos de Coixtlahuaca. Al primer grupo lo presenta como el soporte de un sistema de alianzas 
políticas basado en una red de lazos matrimoniales entre linajes regidos por la primogenitura y el culto a los antepasados. Contrasta el segundo grupo de códices por la importancia central de las migraciones, la zaga del origen legendario en Chicomoztoc, el derecho divino fundamentado en el origen tolteca y el valor ritual de la cacería. El tercer grupo le permite ver cómo, en manuscritos de esa región intermedia y pluriétnica, se combinan características de los dos primeros grupos, con migraciones que ordenan la información y con la inclusión de genealogías. Acaba subrayando las diferencias entre las formaciones políticas de los diferentes grupos analizados, el yya mixteco, el coqui zapoteca y el tecalli nahua.

En sus conclusiones, subraya cómo esos sistemas de información documental están relacionados entre sí a través de lo que considera como una unidad estilística, lo mixtecopoblano, aunque con los ejemplos que ofrece esa supuesta unidad estilística no resulta muy convincente. Para el autor, esa unidad corresponde a una nueva realidad política, social y económica de confederaciones, después de la desaparición de los grandes centros de poder político y religioso del Clásico, tales como Teotihuacan y M onte Albán. Al respecto, si el autor se proponía relacionar sistemas escriturales y realidades políticas, habría sido pertinente comparar los sistemas que analizó con el de Teotihuacan, puesto que, a diferencia de la escritura lográfica zapoteca de M onte Albán, el lenguaje visual de la metrópoli políglota teotihuacana se acerca mucho a los sistemas de registro que estudia el autor. En sus consideraciones históricas, habría sido útil también tomar en consideración la realidad histórica y la complejidad de las migraciones, puesto que los textos que estudia dan tanta importancia a dichas migraciones que los toman como el eje organizativo de toda la composición.

$D$ ana Leibsohn, en "Primers for M emory: Cartographic $\mathrm{H}$ istories and $\mathrm{N}$ ahua I dentity" (pp. 161-187), analiza las relaciones conceptuales entre el altepetl, la geografía y la historia, como bases para la construcción de la identidad sociopolítica en el M éxico central. Para conseguir su propósito, analiza los seis mapas o historias cartográficas relativos a la historia de Cuauhtinchán. Considera así al altepetl de Cuauhtinchán, el cual era pluriétnico con predominancia nahua. Analiza cómo el concepto de altepetl era básico para la autodefinición de su población, con base en un territorio y un gobierno propio. Subraya la ambigüedad de los espacios blancos en esos mapas, que expresan lo mismo tiempo transcurrido que espacio recorrido en una migración o límites y partes de un territorio dado. En lo que concierne a la identidad, anota cómo en los topónimos no figuran ni los teccalli ni los calpullis, aunque los diversos topónimos con los cuales se refieren a Cuauhtinchán reflejan en cierta medida la compleja composición de su población y sus tensiones internas. Indica cómo la selección de los lugares difiere en cada mapa porque se refiere a historias diferentes. Finalmente, subraya cómo esos documentos gráficos destacan entre todos los documentos históricos que conserva aún en la actualidad la comunidad de Cuanhtinchán, aunque se haya perdido el uso de su idioma original.

A modo de comparación con la realidad mesoamericana, T om Cummins y Joanne Rappaport presentan cada uno un estudio sobre el mundo andino. El primer autor, en "Representation in the Sixteenth Century and the Colonial I mage of the Inca" (pp. I88ing), contrasta la situación que privó en Nueva España con la del Perú en cuanto al 
impacto de las imágenes y escritos indígenas en las producciones coloniales. A tal efecto, compara la portada de las $\mathrm{D}$ écadas de $\mathrm{H}$ erre ra, en la cual aparecen antigüedades mexica nas, y la dedicada al antiguo Perú, en la cual el poder colonizador no pudo recurrir al modo de representación andino. Analiza después una crónica colonial que se basó en el testimonio de varios hacedores de quipus, los quipucamayoc, pero que no integró ninguna palabra ni imagen quechua porque la abstracción geométrica misma de esa fuente de información resultaba un obstáculo invencible. Prosigue estudiando una de las imágenes que acompañan al famoso texto de Pachacuti Yamqui, en la cual se reconoce esa misma abstracción. Finalmente, ejemplifica la evolución en la época colonial del par ritual de objetos sagrados, el vaso kero y los textiles, en los cuales desde la abstracción original de los motivos se llegó a representaciones explícitas porque la represión colonial había roto el lazo ritual entre esos objetos sagrados y los cantos, borrando de esa manera el significado simbólico de los motivos abstractos. D emuestra así cómo los diseños abstractos se hicieron iconográficos cuando el pasado se pintaba en esos objetos como forma de resistencia al presente, adoptando, paradojicamente, formas de representación de la cultura dominante.

Joanne Rappaport, en "O bject and Alphabet: Andean Indians and D ocuments in the Colonial Period" (pp. 271-29I), se propone establecer el papel de la escritura alfabética en la colonización de los indios del norte de Perú. Sus fuentes son los documentos legales que nos transmiten una historia filtrada a través de nociones españolas de propiedad privada, de herencia, de transmisión de la tierra y de prestigio. Entre otros ejemplos, cita el caso de documentos fabricados por caciques locales similares a los estudiados por Serge Gruzinski en su Colonisation de l'imaginaire para sostener la función de la palabra escrita en la cimentación de la autoridad de los caciques indios. Aborda el asunto de los objetos simbólicos de poder incaicos (keros y textiles) que ven reforzado su valor en plena epoca colonial, al aparecer anotados por escrito en los testamentos. En sus conclusiones, la autora concuerda con el autor anterior acerca de la evolución de los keros y textiles hacia sistemas de representación iconográficos.

En un largo ensayo, titulado "Signs and their Transmission: the $\mathrm{Q}$ uestion of the Book in the N ew World" (pp. 220-270), W alter $D$. M ignolo analiza los diversos problemas de comprensión que surgieron entre el poder español y los indios mesoamericanos y andinos alrededor de los conceptos del saber y de su transmisión escrita. Se remonta hasta la antigüedad griega para entender lo que significaba el libro, la escritura, el escribano, el sabio y, en general, el poder de la palabra escrita para los españoles, en contraste con la realidad mesoamericana y andina.

En el epílogo del libro, titulado "Afterword: Writing and recorded Knowledge in Colonial and Postcolonial Situations" (pp. 292-312), ese mismo autor ubica el pre sente conjunto de ensayos en el cuadro de una amplia polémica sobre la escritura y su relación con la palabra. Para descolonizar el estudio de las escrituras en América, considera necesario rebasar la obra básica de Derrida invirtiendo la perspectiva y tomando como punto de partida la escritura en M esoamérica y en los Andes, en donde la escritura no estuvo subordinada al habla. Recalca así cómo en el libro se abordaron los sistemas de registro prehispánicos como escrituras alternativas y luego, durante la 
epoca colonial, como escrituras "conflictivas" que participaron de la resistencia al poder colonial. Esa labor historiográfica se queda en un nivel general y no ubica las aportaciones del libro en la evolución del campo específico del estudio de las antiguas escrituras americanas.

En conclusión, Writing without Words ha de considerarse como una significativa aportación en la medida en que ejemplifica la diversidad de los enfoques y la profundidad en la comprensión que puede alcanzarse, cuando se deja de considerar los antiguos sistemas escriturales americanos desde una perspectiva evolucionista etnocentrista y se les reconoce, al contrario, como valiosas opciones de escritura.

Sin embargo, más allá del común interés de los autores por reivindicar el valor de esos sistemas de escritura, el libro carece de unidad orgánica. Así, por ejemplo, no hay una bibliografía general con un índice de citas sino que cada artículo tiene su propia bibliografía. De esa manera, el volumen pierde utilidad como fuente de consulta bibliográfica. Pero, sobre todo, esa falta de coherencia se aprecia en dos aspectos, a mi juicio, particularmente importantes: una carencia de perspectiva historiográfica y una selección no fundamentada suficientemente de los temas presentados y de los descartados.

La comprensible brevedad de cada participación no fue propicia para que los autores ubicaran sus trabajos en la evolución general de los estudios sobre la materia. Como vimos, el epílogo se propone situar los trabajos reunidos en este libro en su contexto historiográfico. Considera como una descolonización mental la valoración de las escrituras alternativas no subordinadas al lenguaje verbal. Sin embargo, este ensayo queda en un nivel general de discusión sobre qué es la escritura y no aborda el mundo particular de los estudios mesoamericanos y andinos.

Por lo tanto, el lector no especialista en el campo específico del estudio de los documentos antiguos estudiados en el libro no encontrará en él los elementos adecuados para apreciar el valor de esas aportaciones. El asunto parece aún más serio al examinar la bibliografía de cada trabajo, donde destaca la gran escasez de publicaciones en español. De tal manera se tiene la impresión de que, en M éxico, después de los grandes iniciadores, se habría perdido casi por completo el interés por ese campo de estudio. 0 bviamente no es el caso. Sin embargo, al cerrar el libro, uno se queda con el inquietante dilema: ison realmente tan escasos las aportaciones recientes en español al respecto, o el mundo académico norteamericano de los mesoamericanistas se encierra cada vez más en una indeseable autosuficiencia?

En cuanto a la selección de los temas tratados, es notable la ausencia de estudios sobre sistemas semasiográficos de los cuales no nos quedan códices sino solamente testimonios a través de la pintura mural, de los relieves y de la cerámica, como son los sistemas de Xochicalco, de Cacaxtla, de Tula y de T eotenango, por ejemplo. Solamente el caso de Teotihuacán está mencionado en la introducción por Elizabeth Boone, pero de modo muy incidental, con el objeto de negar, sin más fundamento, la existencia de una escritura en esa gran metrópoli. Sin embargo, el teotihuacano no se diferencia de los sistemas semasiográficos estudiados en el libro, ni en lo que respecta a sus características formales ni tampoco en su óptima adaptación a las necesidades de una sociedad políglota. Son numerosos los estudios al respecto y los hallazgos de murales en Techinantitla han venido a confirmar el carácter 
escritural del lenguaje visual teotihuacano. Este asunto hubiera iniciado un acercamiento a los sistemas semasiográficos distintos a los tratados en el libro y habría ampliado muy útilmente el panorama histórico de las escrituras alternativas mesoamericanas en su conjunto.

De esa manera hay que considerar el presente libro como un conjunto de interesantes ensayos más que como una obra integrada y exhaustiva. Se trata, pues, de una estimulante invitación a proseguir el estudio de esas escrituras alternativas cada vez más cercanas a nosotros, a medida que se agranda nuestro universo de medios audiovisuales de expresión.

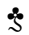 \\ I mágenes de oro. \\ Galería G uatemala II \\ de Luis Lujan M uñoz \\ y M iguel Álvarez Arévalo \\ Guatemala, Corporación $G \& T$, 1993, 200 p., ilus. \\ por \\ ROGELIO RUIZ GOMAR
}

La conveniencia de dar a conocer a los estudiosos mexicanos el bellísimo libro titulado I mágenes de oro, que versa sobre la tan justamente celebrada escultura realizada en $\mathrm{G}$ uatemala durante el periodo virreinal, es lo que me ha motivado a elaborar los siguientes comentarios.

El hablar de este libro en el medio académico de nuestro país me parece necesario y reviste mayor importancia de lo que a prime- ra vista pudiera uno pensar, habida cuenta la, en verdad incomprensible, falta de comunicación académico-cultural que existe entre las naciones de América Latina, y que se traduce en el casi total desconocimiento de lo que se está trabajando o publicando en los paises del área. D oble razón, pues, por la que me congratulo de dar a conocer este libro.

Se trata de una obra de gran aliento y excelente presentación, ilustrada con una generosa selección de fotografías a color de gran calidad. El texto, que se presenta en español y en inglés, está dividido en nueve capítulos. Por los títulos de los mismos es fácil caer en la cuenta del contenido que se pretende abarcar: i. Antecedentes hístóricos, II. G rabados y esculturas, III. Los escultores españoles en el reino de Guatemala, Iv. La escultura en la época colonial, v. Presencia de los pintores: el estofado y el encarnado, vi. Escultura guatemalteca en el exterior, vII. La escuela antigüeña, vIII. I conografía, y Ix. M éxico y Q uito: su escultura barroca. Los seis primeros fueron escritos por el doctor Luis Lujan M uñoz, uno de los más sólidos y reconocidos estudiosos en Guatemala, y toda una autoridad en la materia. A él le correspondió proporcionar la secuencia histórica y estilística de la imaginería guatemalteca, así como hablar de los principales artistas y de los procedimientos técnicos que la distinguen. El séptimo capítulo fue preparado por un equipo, mismo que se preocupó por ahondar en los rasgos distintivos de la imaginería guatemalteca. En él se van sumando párrafos en que se habla tanto de las proporciones de las figuras y de las cualidades expresivas de las mismas, como del acabado que se imprimía a los cabellos, las barbas o las manos, y aún de notas de orden técnico, como puede ser el uso del color, el diseño de los estofados, el encarnado, tipos 
de peañas, etcétera. Por su parte, el entusiasta defensor del patrimonio artístico guatemalteco, M iguel Álvarez Arévalo, fue el encargado de redactar los dos últimos capítulos del libro; effuerzo un tanto abreviado pero sin duda útil.

Siguiendo un criterio cronológico, la información y el material queda organizado con base en las tres etapas en que se ha dividido el desarrollo de la escultura guatemalteca. La primera, o fase inicial, abarca de I525, en que se funda Guatemala, a 1558 , en que se tiene la primera referencia conocida: Juan de Aguirre ejecuta la imagen de la Virgen en el coro en el convento de San Francisco. La segunda etapa, con obras de acento renacentista y manierista, corre desde 1558 hasta 1676, en que está a punto de estrenarse la tercera catedral de G uatemala. La tercera, y última etapa, de corte plenamente barroco, es sin duda la que produjo las obras más significativas, y cubre de 1676 a 1797, en que se establece la Escuela de D ibujo de la Sociedad Económica de Amigos del País.

Cabe señalar que, en general, los autores de los diferentes capítulos abordan con conocimiento y claridad el vasto panorama que había que cubrir. El lenguaje empleado es fluido y le reconocemos a los autores la virtud de no incurrir en la abundancia de adjetivos para poner de relieve la calidad de las piezas.

Se trata de textos más bien cortos y bien escritos, pero un tanto superficiales. $Y$ aunque por momentos el libro está a punto de convertirse en un simple listado o una relación fría de obras y artistas, se adivina que es obra pensada no tanto para el deleite de los estudiosos, sino para difundir en círculos cada vez más amplios, y a muy buen nivel, los valores de la escultura guatemalteca. Convendría por tanto no perder de vista que el libro está concebido más como un válido vehículo de difusión, en el mejor y nada peyorativo sentido del término, que como un instrumento de análisis y de crítica. Esto explica, en buena medida, que el texto se haya querido presentar también en inglés.

D ada la índole del libro, pues, es que hay temas y problemas que hubieran merecido un tratamiento más amplio, pero que se han dejado de lado o se tocan de manera muy superficial. En este último caso está, por ejemplo, el punto de que se trata de un arte las más de las veces anónimo, cuestión que no por conocida deja de ser problemática. Puede que haya sido anónima porque la mayor parte de los contratos 0 encargos se hubieran hecho de palabra, como se aventura en el texto, pero hubiera sido necesario bordar más sobre la cuestión; hubiera bastado proponer, por ejemplo, que la explicación estuviera, en numerosas ocasiones, en el hecho de que el responsable de hacer, verbigracia, un retablo - que es el que sería consignado en el contrato-, hubiese "subcontratado" a otros maestros la hechura tanto de las pinturas como de las esculturas. Lo mismo ocurre con el tema de los procedimientos técnicos, el cual, si bien está tratado en varias partes del texto, hubiera sido deseable armar con mayor coherencia lo que se sabe sobre el particular.

0 tra debilidad, en este caso quizá más evidente para el lector no guatemalteco, es que no se hace el énfasis que merece la originalidad de ciertos temas. Acaso la cercanía y familiaridad ha impedido valorar en su justa medida la singular serie de representaciones pasionarias del $\mathrm{N}$ iño Jesús. En el caso me xicano suele asociársele con la corona de espinas, pero no como en la imaginería gua temalteca, en que gusta representársele cargando la cruz, atado a la columna, e incluso 


\section{76}

crucificado. Se trata de imágenes de enorme fuerza dramática que - quizá me equivoque- - parecen responder a una devoción muy particular y, por lo mismo, merecerían un tratamiento más amplio.

Por lo que toca a aspectos editoriales, es verdaderamente digno de encomio que haya en Guatemala gente no sólo interesada sino capaz de producir libros de tan alta calidad. Edición pulcra, lujosa y exquisita, que, por los costos de producción, obviamente no estará al alcance de todos los bolsillos, con lo que quizá no se consiga en toda su amplitud el deseo de llegar a un amplio círculo de lectores. Se ha empleado magnífico papel, un acertado tipo de letra y de muy buen tamaño, y se ha dispuesto el texto bilingüe en dos columnas. Pero, sobre todo, es necesario resaltar el excelente material fotográfico que más que ilustrar el texto viene a poner frente a los ojos del lector las piezas mismas. Sin embargo, no deja de ser curioso el hecho de que si bien texto y fotografias se ocupan del mismo material, en momentos nos ofrecen dos discursos paralelos, como si hubiesen sido trabajados con cierta independencia. Esto no debe ser considerado necesariamente como un defecto; pero, insisto, hay momentos en que se hubiera agradecido una mayor correspondencia entre texto e imagen. Esa falta de coordinación se deja ver, por ejemplo, en el caso del maestro Juan de Chaves, de quien se reproduce un espléndido San Francisco de Paula (pp. 66-67), pero cuyo nombre sólo se menciona en el texto para atribuirle la bellísima escultura de San Sebastián en la catedral de Guatemala (p. 25); misma de la que se nos ofrecen magníficas reproducciones desde distintos ángulos y en detalles (pp. I19-123), pero que ahí es atribuida a Alonso de la Paz. O bviamente hay un error, pero también podría deberse a una larga discución sobre su paternidad, que el lector no tiene la obligación de saber, quedando confuso sin saber que partido tomar. Pero volviendo a la calidad de las fotografías es necesario resaltar que, además de que son un fiel homenaje al valor artístico de las piezas, permiten una cabal apreciación de ellas, sobre todo cuando se nos ofrece el detalle amplificado de zonas ricamente decoradas, lo que redunda en que crece nuestra admiración por la corrección y la variedad en el diseño de los estofados.

El generoso número de las reproducciones, así como la secuencia y el adecuado diseño en los tamaños y distribución de ellas, imprimen variedad a la impresión y patentizan el buen gusto con el que está preparado el libro. Asimismo, creo que en este caso particular fue un acierto acudir al recurso de recortar por su perfil a las imágenes y así disponerlas sobre el blanco mismo del papel. Eso, y haber colocado las piezas sobre fondos oscuros o muy claros, pero siempre lisos, facilita el poder aislarlas para su mejor valoración; contra lo que pudiera pensarse, este recurso aviva, además, el dorado y la policromía de las piezas.

Entre los pequeños reparos al libro que se me ocurre consignar está el del formato mismo, pues el tamaño escogido dificulta su manejo. Q uizás hubiera sido mejor optar por un libro un poco más grueso pero más chico.

Asimismo, la información que acompaña a las ilustraciones no siempre es completa, especialmente por lo que toca a los aspectos técnicos. Así, uno queda con la duda de si en ciertas imágenes los rostros y las manos también son de madera, o lo son de cera, alabastro, mármol u otro material (v.g., ils. II8, II9 У I20).

A juzgar por la extensión de los textos y 
sobre todo por el lenguaje empleado en ellos, es fácil entender que se trata de un libro destinado a un amplio público. Es así que si bien hay aparato crítico, la verdad es que hay mucha información de la que queda uno sin saber de dónde procede 0 qué autor se ha consultado. 0 tra grave falla es que no se incluye una bibiliografía al final. Cierto es que en las notas se fueron recogiendo algunas obras fundamentales, pero es obvio que no están todas. Con un poco de mayor rigor académico el libro hubiera ganado mucho.

Para terminar quisiera manifestar una legítima preocupación por dos problemas que me parecen capitales y que fueron soslayados en el libro. El primero es la extraña y total ausencia de información sobre la existencia y actución del gremio de escultores y entalladores en Guatemala. Si bien es cierto que en el texto se alude a la tradición gremial - -ampliamente estudiada por $\mathrm{H}$ ector $\mathrm{H}$ umberto Samayoa en Los gremios de artesanos en la ciudad de Guatemala, 1962- , a los autores de este libro no parece preocuparles que justo en el arte donde Guatemala tiene más calidad que ofrecer al mundo del arte hispanoamericano no se conozca nada en torno a la correspondiente organización artístico-laboral de ese arte. ¿D ebemos concluir que no existió gremio de escultores en Guatemala? ¿Cómo explicar, entonces, que sí hubiese gremios para casi todos los demás oficios? Y es que, ien verdad pudo florecer un arte tan exquisito sin el gremio respectivo? ¿Cómo fue que se garantizó la correcta transmisión de los secretos técnicos tan admirablemente conservados en la práctica de tantos años? $\mathrm{Creo}$ que estas u otras preguntas del mismo tenor deberían haber merecido más atención de parte de los autores. $Y$ no olvidar que en alguna ocasion se habla de la transmisión del oficio del padre al hijo, hecho que acaso permita hablar de pequeñas dinastías (v.g., p. 7I).

El segundo problema es en realidad una duda: ise han detectado en la escultura guatemalteca casos de reutilización de cabezas y manos? Esta práctica, como se ha empezado a ver, parece que fue relativamente frecuente en la escultura de la N ueva España. No deja de llama la atención, pues, el hecho de que no haya la más mínima mención de este fenómeno para el caso de Guatemala, pero suena lógico suponer que allí también debió de ser frecuente. En todo caso, resulta conveniente tenerla presente y así evitar la posible ocasión de confundirse en el estudio de las piezas.

Con la aparición de este libro se percata uno de que la escultura guatemalteca, amén de ser un tema apasionante para los amantes de la belleza, es también un área de estudio inagotable por la variedad y calidad de las piezas, abiertas siempre a la posibilidad de nuevos enfoques y aproximaciones.

Felicitamos, pues, encarecidamente a todos los que de una u otra manera colaboraron para llevar a buen fin esta publicación, sin duda la más lujosa y mejor armada sobre la escultura guatemalteca hasta ahora. Siempre serán bienvenidas obras de esta naturaleza, pero dado el éxito que seguramente alcanzará la que ahora comentamos, cabe abrigar la esperanza de que estemos ante el inicio de futuros proyectos de la misma envergadura. 
178

\section{Frederick Edwin Church: $C$ atalogue Raisonné of Art at O lana $\mathrm{H}$ istoric Site,} de Gerald L. Carr

Cambridge U niversity Press, 1994, 2. vols. ilus.

por

CLARA BARGELLINI

El renombrado pintor estadounidense Frederick E. Church viajó con frecuencia a M éxico entre i88г y i9oo. Por eso, la publicación del catálogo razonado de las más de 700 obras de su mano, conservada en su residencia permanente, Olana, en el estado de $\mathrm{N}$ ueva York, es un evento que merece cele brarse, no solamente en Estados U nidos, sino también entre los historiadores del arte en M éxico.

El primer volumen, que es el texto del catálogo, incluye un ensayo del gran conocedor de Church, D avid C. H untington. $\mathrm{H}$ untington murió antes de terminar su estudio, pero el infatigable Carr pudo integrar sus borradores y apuntes en un artículo que examina la calidad estética de las obras de Church. La introducción del mismo Carr sintetiza la información pertinente sobre la vida de Church y la colección de 0 lana. Por supuesto, contiene explicaciones sobre el desarrollo del trabajo del catálogo y sus características. Sigue el catálogo propiamente dicho, dividido en periodos cronológicos sucesivos, de duración variable, de acuerdo a los acontecimiento de la vida del pintor. Cada sección contiene el recuento de la vida de Church en ese periodo, la catalogación razonada de las obras correspondientes e ilustraciones complementarias. El todo con- forma una biografía detallada e íntima, acompañada de los dibujos y cuadros que el mismo pintor conservó en su casa. El volumen termina con una sección sobre los grabados de algunas obras del pintor, con apéndices sobre las características técnicas de otras y, como todo trabajo serio de este tipo, con varios índices. El segundo volumen ilustra todas las obras catalogadas en blanco y negro y los cuadro en color.

Las dos secciones del catálogo que contienen las casi roo obras mexicanas de Church informan ampliamente sobre sus características y sobre las actividades del pintor en M éxico. Gerald Carr ya había presentado esta etapa de la vida del pintor en el Coloquio del Instituto de Investigaciones Estéticas de 1993, que tuvo lugar en Zacatecas. Ahora se tiene la información completa y anotada sobre sus viajes, los dibujos y cuadros que hizo con temas mexicanos, quiénes lo acompañaban y a quiénes veía. Aunque los contactos de Church con la vida cultural del país no parecen haber sido significativos, sí lo eran sus relaciones con otros extranje ros. Todo esto, además de ser un modelo de trabajo, puede ser muy útil para la historia del arte en M éxico. No queda más que agradecer a $G$ erald $C$ arr sus años de dedicación y trabajo, que nos han proporcionado un material tan interesante y valioso. 


\section{Cine y sociedad en M éxico, 1896-1930. Volumen II: Bajo el cielo de M éxico (1920-1924) de Aurelio de los Reyes}

M éxico, Instituto de Investigaciones Estéticas, Universidad N acional Autónoma de M éxico, 1993, rx y 409 p., ilus.

por

ÁLVARO MATUTE

D espués de un intervalo de doce años - tomando en cuenta las fechas de pie de imprenta- aparece el segundo de los tres volúmenes que Aurelio de los Reyes ha consagrado a la interacción entre cine y sociedad en M éxico, durante el tiempo en que el arte cinematográfico era silente. Como el anterior, es un libro de gran formato, profusamente ilustrado con fotografías provenientes de las propias películas estudiadas, de diarios y revistas, y de archivos. M uchas de ellas eran inéditas. El nuevo libro se complementa con uno, de formato menor, dedicado a rescatar la filmografía de la época, cuya originalidad es definitiva (Aurelio de los Reyes, Filmografía del cine mudo mexicano, volumen II, 1920-1924, M éxico, U niversidad N acional Autónoma de M éxico, Dirección General de Actividades Cinematográficas, 1994). Pese a que es equivalente al fichero del primero, se puede leer de manera independiente, ya que se trata de una obra de carácter informativo sobre un objeto de estudio acerca del cual se ha investigado muy poco. Pese a su modestia, es una aportación por sí misma.

D esde luego, la obra mayor es la que reclama toda la atención. Se trata, como ya quedó dicho, y como fue establecido desde el volumen primero, de la relación sociedadcinesociedad. Es decir, la premisa de la que se parte implica que el cine se nutre de la realidad social y que se revierte hacia ella, formando una serie de círculos concéntricos. Así, por ejemplo, una acción particular, proveniente de un contexto histórico-social determinado, al ser captada por el cine, ya sea como documental o como representación artística, se universal iza y llega a ámbitos distintos de aquel que los originó, convirtiéndose en modelos e incluso en paradigmas, estereotipos, mitos.

Para emprender el trabajo, Aurelio de los Reyes parte en esta ocasión del contexto que le proporciona la historia política, esto es, el arribo de los hombres de Agua Prieta al poder, con los gobiernos de los dos primeros vértices del triángulo sonorense, Adolfo de la $\mathrm{H}$ uerta y Álvaro O bregón. Si bien en el primer libro el porfiriato y la revolución son el gran fondo contextual, no deja de llamar la atención la acotación precisa de los periodos de los dos sonorenses, con lo cual se espera que el próximo volumen abarque el gobierno de Calles y el principio del maximato.

La situación se explica pronto, porque no se trata de una historia formal de los gobiernos sino la de los imaginarios que se producen en el género chico, desde luego en el cine y en parte de la prensa. Los títulos de los capítulos provienen de obras cinematográficas o de otros géneros de representación. Así, se inicia la obra con "Los tres alegres compa dres" y prosigue con "La huerta de don Adolfo", para más adelante abordar "El jardín de $\mathrm{O}$ bregón" y concluir con "M i candidato", que es el preámbulo y desarrollo del rompimiento entre los sonorenses y la rebe lión delahuertista. En otro tenor, hay capítu- 
I80

los de política social, como "Río Escondido"; sobre la educación, y "Bolshevikismo", sobre los trabajadores, donde De los Reyes hace interesantes aportaciones sobre la doctrina social de la iglesia católica. En ellos está la circunscripción política del libro y lo que se desprende de ella en la imagen recuperada. La sociedad, en su mayor amplitud, aparece en "La muerte enamorada", concierto de autoviudas; "Cuando la patria lo manda", de asunto nacionalista, directamente relaciona do con la política de exhibición cinematográfica; "Bajo el cielo de M éxico", que recoge temas diversos propuestos por la imagen; "M adre querida", donde predomina la pre sencia de la mujer, y "Revista O limpia", referido a lo que veía la gente en la pantalla y a cómo se veía la gente de entonces en sus diferentes versiones y actividades. De mane ra esquemática, tal es el contenido del libro. Además de la acotación temporal, la espacial es prácticamente la ciudad de M éxico, como el propio autor lo reconoce en su introducción. Asimismo, es cierto que los capítulos podrían ser, cada uno de ellos, un libro independiente. Afortunadamente, sin embargo, se encuentran reunidos y relacionados entre sí.

0 tra nota digna de mención es que, contrariamente a lo que hacen otros investigadores de temas extraños a la realidad política y social, Aurelio de los Reyes no se va por el camino fácil de estudiar el contexto en fuentes secundarias y sólo abordar su objeto directo con las primarias. Por el contrario, su investigación es igualmente original, es decir, basada en fuentes directas para lo uno y lo otro. Claro que tiene apoyos, pero predomina el trabajo directo. La pertinencia de la prensa como fuente mayoritaria la determinan los temas tratados. Llama la atención lo que aporta de conocimientos sobre los ámbi- tos político y social, así como en el plano interpretativo.

Lo que podría captarse como estructura profunda del texto es la ya descrita interrelación entre la imagen y la realidad. Eso lleva al autor, y él, a su vez, al lector, a una realidad más cotidiana que la del historiador de la política y más real que la del historiador de la sociedad, que tiende a abstraerla. Sin estar adscrito a una tendencia definida de la historia de las mentalidades, los partidarios de ella tienen en este libro una buena muestra para la primera mitad de los años veinte. Aunque, insisto, no es una historia de las mentalidades ni mucho menos de la vida privada. Es un puente entre ellas y la esfera pública, la esfera de lo que trasciende de la una hacia la otra, en los dos sentidos, de lo público a lo privado y de lo privado a lo público. M e explico: el interesante capítulo de las mujeres que deciden acabar con la vida de novios o esposos es una historia de una relación privada que llega al dominio público principalmente por la prensa. Se convierte en un espectáculo al igual que la acción de los gobernantes, de quienes se que rría saber lo más recóndito. El seguimiento de los casos hace que se indague sobre los orígenes 0 "causas" y se presenten los entramados típicos: exposición-nudo-desenlace, que un público ávido sigue como si se tratara de una representación. En otros capítulos, el entramado narrativo es sustituido por el repaso de tipos y estereotipos, la madre, el obrero, el maestro, el político, etcétera, a veces en acciones, a veces en sí mismos. Con ello se puede asistir a una enorme galería de distintos mexicanos de la época de 0 bregón y de acciones sucedidas en ella.

En cuanto al estilo del autor, en ocasión anterior lo definí como barroco, partiendo de la idea que comunicaba Francisco de la 
$M$ aza en sus lecciones, como "horror al vacío". No es que Aurelio de los Reyes sea barroco en su forma de escribir, es barroco por su horror a dejar sin llenar el hueco mínimo. Su acercamiento a las fuentes es modelo de acuciosidad y de obsesión. No quiere que ningún tema quede desprotegido. 0 tro rasgo estilístico de los libros del autor es su concepción fílmica de ellos. En su manera de organizarlos, se puede hablar de montaje. La manera como comunica los resultados de sus investigaciones tiene mucho que ver con el lenguaje cinematográfico. De ahí que no generalice, sino que siempre Ilene sus pantall las. La fotografía sobre la cual fue diseñada la portada del libro lo expresa cabalmente: es una sala cinematográfica abarrotada. No cabe en ella un alfiler y todos los presentes están ávidos de mirar la pantalla de que les llenen su tiempo con algo digno de ser contado. Están impacientes de que se oscurezca la sala y comience la función.

j

\section{South of the B order: Mexico in the American Imagination; 1914-1947} de James 0 les

Catálogo de la exposición en la Yale U niversity Art Gallery, introducción de Karen Cordero Reiman, W ashington, Smithsonian Institution Press, 1993, 296 P., ilus.

por

RENATO GONZÁLEZ MELLO

En el catálogo de esta exposición, James 0 les ha abierto un nuevo tema de búsqueda.
La investigación que dio origen al proyecto es la del doctorado del autor, que esperamos ver terminado y publicado en breve; por lo pronto, y sin haber visto la muestra, me limito a reseñar el catálogo. $M$ erece una mención, aunque sea breve, el ensayo introductorio de Karen Cordero, que resume para el público no iniciado la historia del arte mexicano en la primera mitad del siglo xx. La intención de ese texto es mostrar el conocimiento ya adquirido por el gremio. En tal sentido, es satisfactorio constatar que los viejos prejuicios ya han dejado de ser repetidos, que todo intento de resumen es, por fuerza, una interpretación nueva sobre datos muchas veces también nuevos.

South of the Border no trata, como promete el subtítulo, todos los avatares de M éxico en la imaginación norteamericana, pero hinca el diente en una provincia importante y desconocida de ese vasto campo de estudio: la labor de los artistas estadounidenses, o residentes en Estados U nidos, que viajaron a M éxico y de alguna manera cambiaron su actividad debido al conocimiento de las artes y la vida de nuestro país. En el intercambio entre las artes de $N$ orteamérica y las de $M$ éxico, estamos acostumbrados a ver con algo de condescendencia a la cultura norteamericana; como si, efectivamente, los pintores mexicanos hubieran encontrado el vacío en Estados Unidos y los gringos que venían a estudiar con Diego Rivera hubieran sido discípulos obedientes y triviales. El lamentable estado de conservación del mural de Phillip Guston y Reuben Kadish en el M useo Regional de M orelia es un símbolo de esa incomprensión y de ese desprecio, del que bien podemos avergonzarnos. James 0 les procura enderezar la situación: los norteamericanos que venían a M éxico tenían sus propias intenciones y no siempre recibieron pasivamente lo que les 
182

ofrecía el país. Aunque a veces hayan sentido una gran admiración por el vigor de las artes mexicanas después de la revolución, ese aprecio no se dio lejos de la crítica.

El viaje a M éxico era algo muy parecido a lo que, para los europeos del norte y para los ingleses, fue el viaje a Italia: la huida de una "civilización" industrial hacia una tierra que se suponía ajena a tales progresos. La revolución era "expresión" de un alma bronca, como se la había figurado J ohn Reed en su retrato de Francisco Villa, y los norteamericanos apreciaban esa sinceridad, que les parecía superior a la vida moderna. M uchos de ellos llegaron a M éxico después de buscar el paraíso perdido entre los indios de Nuevo M éxico y Arizona; otros fueron empujados a nuestro país por la histeria anticomunista de la primera posguerra. En cualquiera de los dos casos, su peregrinación no era inocente, tal como se ve en sus obras.

O les contrasta, a lo largo de todo el catálogo, dos tendencias en el arte norteamericano sobre M éxico. Por una parte, algunos artistas esquematizaron e idealizaron la realidad mexicana: M éxico era la Arcadia; sus artes eran motivos meramente geométricos 0 decorativos, lo mismo que sus mujeres; el pueblo mexicano no sufría los terribles conflictos de la modernidad. Tal hicieron, en diversos grados, Irwin $\mathrm{H}$ offman, D oris Rosenthal, Thomas $\mathrm{H}$ andforth, $\mathrm{H}$ oward Cook, Edward W eston y Henrieta Shore. 0 tros artistas mostraron un país menos amable, atacado por numerosos males sociales 0 de plano inmerso en la lucha de clases. Es el caso de Pablo 0 'H iggins, $M$ arion y Grace G reenwood, Isamu N oguchi y Paul Strand (en Redes). La historia de O les no es de buenos y malos: muchos de sus artistas, particularmente los fotógrafos Paul Strand y Anton Bruehl, tuvieron distintas actitudes, dependiendo del contexto en el que se desarrollara su actividad.

Es particularmente afortunada la confrontación de obras de arte en el catálogo. Por ejemplo, O les pone página contra página la famosa foto de Weston, M ano de Amado Galván, aparecida junto a la portada de Idols Behind Altars, donde el alfarero eleva ante la cámara una pieza que acaba de terminar, y la fotografía de Bruehl, $\mathrm{H}$ ands of the Potter, que muestra las manos de un alfarero, cubiertas de barro, trabajando en una maceta. Esta última es una foto tomada desde arriba; la de W eston, desde abajo. La foto de Bruehl muestra el trabajo artesanal como al go modesto y orgánico, ligado a la materia; el Amado Galván de W eston es un personaje heroico que eleva su pieza como si fuera una ofrenda al sol. Así se acomodan las ilustraciones a lo largo del libro. Las reflexiones de Oles, aunque siguen su propio curso, van hilvanando estas oposiciones.

Las limitaciones propias de un catálogo de exposición impiden al autor desarrollar muchos problemas que quedan solamente insinuados o planteados. V oy a señalar solamente las que me parecen más significativas.

En la útil sección final, donde se incluyen biografías de los artistas que vienen al caso, puede seguirse una historia paralela que echamos de menos en el texto principal: la de las galerías y los promotores, los puntos de reunión y de exposición. Los nombres de Carl Zigrosser, la W eyhe Gallery y los D elphic Studios aparecen repetidamente en diversas biografías. Cada una de éstas incluye una breve, excelente lista de referencias bibliográficas y hemerográficas que dan más que pensar. $\mathrm{N}$ uevamente hay nombres que se repiten, especialmente el de Guillermo Rivas, que publicaba crítica de arte en la revista M exican Life. Aunque algunos impor- 
tantes autores son considerados en el ensayo de O les, como es el caso de Anita Brenner, habría sido conveniente seguir más de cerca a otros críticos.

El texto de O les le presta toda su atención a las obras; las analiza y las interpreta a partir de lo visible. D espués, muy de acuerdo con lo que se hace actualmente en Estados U nidos, busca la dimensión política de las obras, aun en aquellas que en apariencia no la tienen. Así, el famoso mural de $\mathrm{H}$ oward Cook para el $\mathrm{H}$ otel T axqueño es señalado como un ejercicio escapista (representa a unos niños rompiendo una piñata). La idealización de la vida cotidiana en M éxico llegó a tal punto que a veces los campesinos e indios representados eran geometrizados: eran el indio abstracto. 0 les no se hace ilusiones sobre el mayor realismo de las representaciones fuertemente políticas de las Greenwood, por ejemplo, cuya imagen de país en lucha no carecía de un alto grado de idealización.

Visto desde fuera, el problema también parece tener otra dimensión. Sorprende en las obras de los norteamericanos la obsesión repetida por encontrar dos mundos: el de la vida cotidiana y el de la política activa y heroica. Las idealizaciones, con mucha frecuencia, se dieron en el primer campo. Por ejemplo, el mural de George Biddle en la Suprema Corte de Justicia presentó a un ángel que custodiaba una familia casi sagrada; en el fondo, un valle promisorio esperaba el futuro. Fue también este terreno de la vida cotidiana, en el que la política aparentemente no existe, donde la crítica norteamericana fue más feliz: por ejemplo en las fotos de D orothea Lange y $\mathrm{H}$ elen Levitt, $\mathrm{O}$ en algunos cuadros de Pablo $\mathrm{O}$ 'H iggins.

$\mathrm{N}$ i siquiera este último dejó de hacer algunas representaciones de feliz vida cotidiana, como en el extraordinario fresco de
Ios futbolistas, en la escuela Estado de $\mathrm{M} \mathrm{i-}$ choacán, de 1940. O les revisa las pinturas de ese artista en el mercado Abelardo Rodríguez, de 1934 a 1936, las cuales muestran la lucha política con un sentido francamente pesimista. Esta diferencia se podría explicar por el tiempo transcurrido entre 1934 y I940 o por los distintos contextos (un mercado y una escuela), pero me pregunto si la política y la vida cotidiana no formarían parte del mismo proyecto; si la existencia feliz que los norteamericanos querían ver en M éxico no sería complementaria de la lucha social, en vez de ser su opuesto. La política y la familia se ven distintos porque su dimensión histórica lo es: la paz en la familia y la comunidad, y la guerra fuera de esos ámbitos no son imágenes que necesariamente se excluyan.

Sólo resta desear que, gracias a trabajos de investigación serios como éste, las políticas oficiales moderen un poco su acendrado chauvinismo y se considere que también es prioritaria la conservación de las obras realizadas por los norteamericanos en M éxico.

\author{
s \\ The $\mathrm{H}$ istory of Art $\mathrm{H}$ istory \\ de U do Kulterman \\ N ueva York, Abaris Books, 1993, 278 p., ilus. \\ por \\ LOUISE NOELLE
}

La existencia del arte y su reconocimiento se ha dado desde la antigüedad clásica; sin embargo, su historiografía se remonta tan 


\section{I84}

sólo al Renacimiento. Aun más, la historia del arte como una disciplina independiente nació en el siglo pasado y en la actualidad no cuenta todavía con el total reconocimiento de ciertos intelectuales. D entro de esa polé mica, que busca negar la importancia de la historia del arte, cobra especial importancia este libro que demuestra fehacientemente la relevancia histórica de su existencia.

En efecto, $U$ do Kulterman no pretende demostrar de manera teórica o filosófica la realidad de esta forma del conocimiento; su propuesta es revisar las aportaciones que han realizado los historiadores del arte a lo largo de la civilización, estableciendo así su indiscutible presencia y su indudable utilidad. Cabe agregar que este estudio, aparecido en 1993, tiene su antecedente en una publicación en alemán, lengua nativa del autor, intitulado Geschichte der Kunstgeschichte y edita do en Düsseldorf por Econ-Verlag G $\mathrm{mbH}$ en I966. De este modo, el trabajo bien puede inscribirse dentro de la tradición alemana iniciada por Johann Joachim W inkelmann y que ha tenido destacados pensadores a lo largo de los doscientos cincuenta años que siguieron. También es útil señalar el reconocimiento que ha obtenido Kulterman dentro de los círculos de estudiosos del arte y la arquitectura contemporáneos, preocupándose por recoger, en sus veinticinco libros y más de quinientos artículos, el quehacer de artistas de diversos puntos del orba. 0 bras como Arquitecura contemporánea en Europa oriental, Architecture in the 20th Century y $\mathrm{N}$ ew in African Architecture le permitieron obtener la Cátedra Ruth y N orman M oore en la U niversidad de W ashington en San Luis M issouri, donde desarrolla su actividad docente.

A lo largo de casi trescientas páginas se encadenan hábilmente arte, historia, teoría, estética, artistas y biografías, para conformar un cuerpo coherente de conocimiento y su desarrollo hasta nuestros días. Veinte capítulos nos llevan desde "las vidas de artistas" de Giorgio Vasari, hasta maestros y colegas contemporáneos como G eorge Kubler, D iego Angulo y Bruno Zevi entre los primeros, y Linda N ochlin, Irving Lavin, Joseph Rywert y Jorge Glusberg de entre los últimos. Buen número de ilustraciones muestran a estos estudiosos del arte, completándose la publicación con una bibliografía básica y un índice de nombres.

Sin duda alguna se trata de una obra fundamental para la comprensión y el estudio de la historia de arte, que deberá convertirse en un libro de texto obligado para los al umnos que cursen esta carrera. De la mano de este erudito podremos recorrer las propuestas de los franceses de la primera mitad del siglo xviri y su relación con la Ilustración a finales de ese mismo siglo, comprenderemos el papel decisivo de la publicación, en 1764 , de Geschichte der Kunst de Altertums y de los demás escritos de W inckelmann, que no sólo levantaron una fuerte polémica en Roma sino que también revolucionaron definitivamente los estudios sobre el arte. Las aportaciones de filósofos como Immanuel Kant y $\mathrm{Georg} \mathrm{H}$ egel se interrelacionan con las actividades de $\mathrm{Q}$ uatremère de $Q$ uincy a favor del clasicismo y los escritos históricos de J ohann $G$ oethe; además se analiza el romantisismo de figuras como John Ruskin y el significado de la Escuela de Berlín, donde posteriormente cobran relevancia Jakob Burckhardt y $\mathrm{H}$ einrich Wölfflin.

D entro de la brevedad que corresponde a una reseña, es imposible recorrer la linea del pensamiento que ofrece este libro, por la riqueza de los conceptos y la amplitud de 
datos. Sin embrago, es posible señalar que el autor no sólo conoce los caminos de otros tiempos sobre el pensamiento acerca del arte; asimismo, ha sido capaz de desentrañar las tendencias actuales y sus principales exponentes. Con singular profundidad analiza la postura de los principales historiadores actuales, señalando sus antecedentes y sus aportes y tratando las líneas que los ligan 0 los separan. N uevas perspectivas como la iconología o la semiótica, así como las visiones regionales, encuentran su sitio dentro de los últimos capítulos, donde queda manifiesto un amplio conocimiento de la situación en las postrimerías del siglo $\mathrm{xx}$.

Un épilogo sobre "La imagen del histo- riador del arte" cierra la publicación incorporando al lector dentro del círculo de investigadores del arte y comprometiéndolo con una larga tradición de destacados estudiosos. De este modo, se presenta un libro que no busca un reconocimiento fácil del público en general, y que ofrece más bien al especialista todo un ámbito de conocimiento y reflexión. Este cuidadoso recorrido por los derroteros de la historia del arte ofrece no sólo un acervo informativo pertinente; asimismo, abre las puertas de esta disciplina a las jóve nes generaciones de académicos que habiendo estudiado el pasado puedan proponer los estudios que expliquen y estimulen al arte del siglo por venir. 